\title{
MODA: EXPRESSÃO DE ARTE E DESIGN
}

\section{FASHION: ART EXPRESSION AND DESIGN}
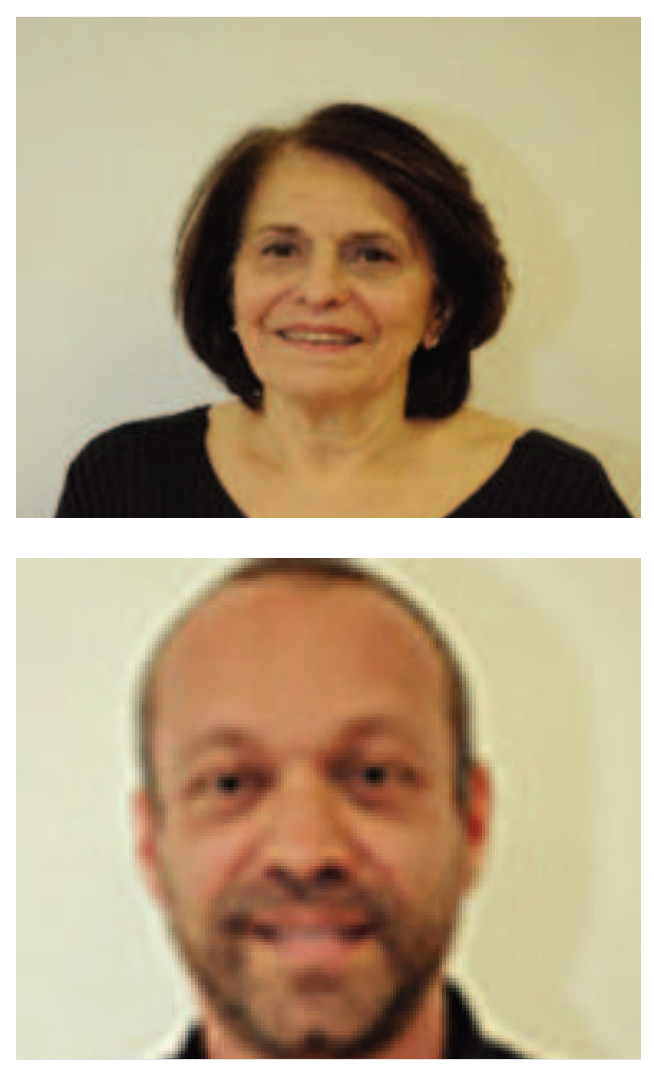

\section{Ione Bentz}

Doutora em Linguística e Semiótica pela Universidade de São Paulo

Programa de Pós-Graduação em Design, Universidade do Vale do Rio dos Sinos

ioneb@unisinos.br

\section{Fábio Parode}

Doutor em Estética pela Université de Paris 1 - Panthéon

Sorbonne

Programa de Pós-Graduação em Design, Universidade do

Vale do Rio dos Sinos

fparode@unisinos.br

\section{RESUMO}

Este texto promove o diálogo entre moda e arte, inspirado em processos criativos de design, para análise da coleção do estilista Ronaldo Fraga cujas peças fazem a releitura do pintor Cândido Portinari. Esse diálogo é produzido pelos traços de intertextualidade que organizam a narrativa imagética, cujas peças e telas constituem a base da observação empírica. As significações materializamse em duas linguagens, também em sinergia: a imagética e a verbal. Para fins de análise, essas linguagens operam dois micro-processos: um, de ordem referencial ou de representação, outro, de ordem simbólica. Organizados em substratos, os materiais/artefatos/sistemas, são assim categorizados: a) as representações simbólicas: substratos representativos dos interesses sociais; (b) os processos de inovação: comunidades interpretantes; e (c) as estratégias de inovação social: mediações tecnológicas. As narrativas, portanto, seriam organizadas pela gramática dos símbolos, das interações colaborativas e das estratégias projetuais. Esse conjunto de referências é capaz de articular o diálogo transdisciplinar proposto.

\section{PALAVRAS-CHAVE \\ Moda. Design. Arte.}




\section{ABSTRACT}

This text proposes a dialogue between fashion and art, inspired by design creative processes, to analyze the collection of designer Ronaldo Fraga, whose work redefines that of the painter Cândido Portinari. This dialogue is produced through traces of intertextuality, which organizes the narrative imagery, the work/design items and canvases of which form the basis of empirical observation. The significances materialize themselves both into two languages and synergy: the imagery and the verbal. For analytical purposes, these languages operate with two micro-processes: one in a referential order and the other in a symbolic order. Organized into substrates, the materials/artifacts/systems are therefore characterized as: a) symbolic representations: representative substrates of social interests; (b) innovation processes: interpretants communities; and (c) social innovation strategies: technological mediations. The narratives, however, should be organized by the grammar of the symbols, the collaborative interactions and the projectual strategies. This conjunction of references is capable of articulating the proposed trans-disciplinary proposal.

\section{KEYWORDS}

Fashion. Design. Art.

\section{INTRODUÇÃO}

A centralidade nos processos é fundamental na organização das reflexões apresentadas neste texto. Embora processo e produto formem uma dualidade indissociável, acredita-se que a compreensão dos processos produz uma percepção abrangente das realidades e, simultaneamente, o olhar sobre os produtos favorece a identificação das mudanças e das descobertas. Compreendida a inovação como processo de ressignificação (Verganti, 2008), é ela que articula significados, interpretações, cenários, métodos ou projetos. Em consequência, ganha expressão na pesquisa em design.

Marcam esse tipo de investigação as seguintes balizas: (a) a temporalidade simultânea - que pensa o mundo como ocorrência futura, síntese dos tempos anteriores ou presentes; (b) a espacialidade, refém do reconhecimento, nem que seja temporário de um território ou de seus limites; (c) a pluralidade das forças em disputa na construção dos exercícios de poder, reconhecidas, apesar de estrategicamente escondidas; (d) a materialidade como um dogma da racionalidade, nem verdade, nem realidade, nem totalidade; (e) o espírito, o desejo, o sonho e a utopia como ingredientes de uma história que se quer contar; (f) a história como projeto de narrativa, já que está sempre em busca de uma síntese que não passa de fragmentos em permanente reorganização, a produzir outras tantas e diferentes narrativas; e g) o esforço de produção de um equilíbrio, mesmo que temporário, resultado do processo projetual que, entregue às diferentes leituras, se expressa na liberdade que a cadeia infinita de interpretantes possibilita.

Há, entretanto, um processo que organiza essas leituras e lhes confere reconhecimento: o processo da intertextualidade. Percebido a partir dos efeitos de sentido (Zurlo, 2010), desenha-se uma linha de redundância, de elementos que reiteram no espaço textual, capaz de garantir a identidade ou o reconhecimento dos sentidos em produção. $O$ conceito de intertextualidade, trazido à literatura por Derrida (2013) é simples e de uma ordem de operacionalidade relevante para o estudo das práticas projetuais de design, o que justifica a busca de uma fonte clássica de referência, pois favorece ressignificações diretamente nela inspiradas. Esse conceito leva à identificação de traços de redundância presentes em diversos pontos dos espaços textuais em análise, sejam eles de natureza contextual (dados estáveis reconhecíveis) ou situacional (ocorrências circunstanciais eventuais), que vêm a constituir o núcleo das operações significantes atualizadas nos processos criativos projetuais. São também esses traços que estimulam as práticas de 
produção de cenários ou de protótipos.

Foi nessa direção que se desenvolveu o diálogo entre moda, arte e design, mais especificamente pela aproximação da coleção do estilista Ronaldo Fraga cujas peças (Coleção Verão 2015) fazem a releitura do pintor Cândido Portinari. Esses artistas, nas Figuras apresentadas ao longo deste texto, aparecem referenciados, respectivamente, como (RF) e (CP). Retomem-se alguns dados para contextualização desses autores no universo da criação em moda.

Estilista brasileiro contemporâneo, nascido em Minas Gerais, Ronaldo Fraga possui formação e especialização no Brasil e no exterior, é profissional premiado e de reconhecido prestígio. Destaca-se entre os estilistas brasileiros pelo caráter crítico de sua obra, perpassada pelos ícones da cultura brasileira. Sensível à realidade social, está atento aos processos de discriminação ou exclusão social e aos acontecimentos da sociedade e da cultura latino-americana ou internacional.

Cândido Portinari, nascido no início do século, e prematuramente falecido aos 58 anos (1962) é um dos artista plásticos mais prestigiados do Brasil, com projeção internacional. Nascido no interior de São Paulo, em uma fazenda de café, viveu uma realidade desfavorável, mas não capaz de ofuscar seu dom natural para a arte. Com passagem pela Escola Nacional de Belas Artes, Rio de Janeiro, destacase pela sua arte, filiada ao movimento modernista então considerado marginal. Com experiências no exterior, sua estética evolui para a valorização mais das cores e das ideias do que de volumes, na esteira de interesse pelas causas sociais que incorporara a seus valores. Por não ter sido relevante para este trabalho percorrer o acervo de cerca de 5000 obras, das pinturas a óleo aos murais e afrescos, é suficiente posicioná-lo no cenário da cultura brasileira como um grande pintor e um cidadão compromissado com as questões sociais que preocupam a sociedade.

Ronaldo Fraga, por sua vez, nessa coleção específica, cria moda com exploração das raízes pelas memórias de infância, em parte motivada pelo acesso aos escritos de ' $O$ caderno secreto de Cândido Portinari', e ressignifica, nas cores e nas formas, o modo como o pintor retratava o homem do campo, sua cidade natal, os costumes dos brasileiros, desde as brincadeiras ou festas populares ou infantis e outras tantas manifestações de cultura. Pode-se dizer que a obra de Portinari é um verdadeiro legado da memória brasileira.

É nesse enquadramento - telas-quadros/murais/afrescos e telas-corpo- que esses dois artistas são colocados em interação: diferentes e criativos, expressam na plasticidade a sua inspiração nas raízes de brasilidade.

\section{PONTO DE VISTA E PERCURSO INVESTIGATIVO}

As teorias estão para as práticas como as práticas para as teorias, sendo que os achados transformadores são encontrados nas realidades práticas. Para reconhecê-las, é preciso escolher formas de olhar ou pontos de vista que transcendam o percebido, em busca do que está apenas intuído ou sugerido. Esse tipo de pensamento, na sua origem, sempre se entendeu como plural, pertinente às chamadas ciências sociais e referente à cultura, termo esse que nomeia o conjunto de produções humanas (objetos culturais), ou a maneira de viver de uma sociedade. Esse conjunto contém em si vários outros sistemas que correspondem às instituições sociais e seu funcionamento, em escopo amplo que vai das linguagens aos regimes políticos e às práticas cotidianas, das regras sociais aos rituais e mitos que estão na raiz do sentir, do saber e do fazer humanos. Busca-se, assim, pelas observações empíricas, desenhar uma gramática do conhecimento humano cujas regularidades sistêmicas responderiam aos modos de pensar e produzir bens culturais ou representar fenômenos naturais. Essa ordem de racionalidade parte de noções configuradoras do sistema, como totalidade, solidariedade e autonomia, e opera, metodologicamente, por identificação de descontinuidades e por descrição de diferenças, em busca de combinatórias e permutas intra-sistêmicas, sempre na perspectiva relacional.

Esse processo refere uma relação de interatividade também presente na prática 
metaprojetual e de cuja complexidade decorre seu potencial gerativo e heurístico. Esse tecido textual é chamado de narrativa, no sentido de que essas estruturas se dispõem a contar histórias. Essa aproximação justifica-se pelo fato de considerar as narrativas instâncias de reconhecimento capazes de explicitar estratégias de ver, de prever e de fazer ver, portanto, serem de interesse dos processos de projetação do design. É nessa perspectiva (ZURLO, 2010) que ver corresponde à capacidade de enxergar fenômenos para além do que é visível (significados implícitos), de modo a permitir a exploração mais ampla e precisa dos quadros de referência cultural. Já a condição preditiva (a de prever) opera com a identificação de índices que sinalizam o devir e que permitem identificar necessidades futuras e pensar a inovação. Por outro lado, a visibilidade do fazer ver explicita as projeções para a construção de uma narrativa projetual coerente. Portanto, relacionar o ato de projetar ao ato de narrar tem toda a pertinência.

O processo projetual cria uma narrativa-síntese do ser e do dever ser; a estratégia em que essa narrativa projetual pretende operar, corresponde, via de regra, aos sentidos postos e pressupostos, lineares ou subliminares, processos praticados pelos sujeitos na operação das linguagens. E, sendo o sujeito um parâmetro metalingüístico independente de qualquer enunciado concreto, é nele que as práticas sociais se materializam. Ora, práticas são unidades complexas significantes e um de seus modos de manifestação é a narrativa. Assim, "histórias são contadas pelas linguagens; pensamentos, sentimentos e percepções são compartilhados também pelas linguagens" (PRADO COELHO, 1968, p. XV).

Contar histórias (narrativas) sobre a moda leva a considerar linguagens e produção de sentidos (efeitos) como centrais para delimitação dos percursos investigativos. Considera-se que há três universos - moda, arte e design - a serem considerados. São universos factuais e discursivos que tem uma ordem de reversibilidade entre si, donde resulta uma sempre atual totalidade significante. As significações materializam-se em duas linguagens, também em sinergia: a imagética e a verbal. Elas obedecem a sistemas distintos em sua natureza: a primeira é de natureza analógica, não-discreta e difusa; a segunda, de natureza imotivada, discreta e sucessiva (de apreensão temporal). Para fins de análise, essas linguagens operam dois micro-processos: um, de ordem referencial ou de representação, outro, de ordem simbólica, sendo esse o de maior relevância para o estudo dos efeitos de sentido, por ser o espaço da conotação o mais dinâmico e criativo das linguagens.

Parte-se do princípio que toda a operação significativa relevante é simbólica (ou conotativa) e que o que é reconhecido como denotação (processo primário de significação) assume em relação à conotação apenas o papel de um primeiro nível de condição primária. O processo simbólico é sempre um segundo nível de linguagem, correspondente ao nível metalinguístico. Essa posição teórica repercute, inclusive, na compreensão da dualidade realidade/ficção, uma vez que, mesmo ao representar a realidade, a linguagem imagética ou verbal opera simbolicamente na produção da semiose; repercute, também, por extensão, sobre processos projetuais de inovação, resultantes que são de um processo de semiose.

Organizados em substratos, os materiais/artefatos/sistemas, assim seriam formulados: a) as representações simbólicas: substratos representativos dos interesses sociais; (b) os processos de inovação: comunidades interpretantes; e (c) as estratégias de inovação social: mediações tecnológicas. As narrativas, portanto, seriam organizadas pela gramática dos símbolos, das interações colaborativas e das estratégias projetuais. Esse conjunto de referências pode articular o diálogo transdisciplinar entre Moda, Arte e Design.

\section{MODA, CORPO E SIGNIFICAÇÕES}

Para expressão do diálogo que entre si estabelecem Ronaldo Fraga e Cândido Portinari, optou-se por selecionar excertos da Coleção Verão 2015 e obras de 
referência que inspiram o vestuário. As semioses que as imagens produzem são representações simbólicas de natureza narrativa que se oferecem aos interpretantes. Os sentidos por ela produzidos transcendem os corpos e os estilos; as estratégias de inovação estão nas releituras cuja semiose (processo de produção de sentidos) elege ícones-sínteses para estruturar a mensagem.

Parte de uma pesquisa maior em desenvolvimento, optou-se por selecionar as figuras/imagens apresentadas neste trabalho, apenas parte de um material mais amplo e diversificado. Por tratar-se de moda e vestuário, parece oportuno recuperar a compreensão que Barthes (2009) tem da linguagem do vestuário. Esse sistema pode ser trabalhado como sistema real (ou visual) ou como sistema escrito, ou seja, como objeto real ou como objeto escrito. De certa forma, o trabalho se situa não entre o vestuário ou a linguagem, mas se ocupa de analisar a tradução de um para outro. É assim, como diálogo entre sistemas de signos expressos em diferentes códigos, que a moda se significa como expressão de cultura. Nesse processo, surge toda a ordem de influências e de hibridizações que alimenta o imaginário e estruturam o simbólico. O importante é que sua substância é inteligível. "Não é o objeto, é o nome que faz com que se deseje: não é sonho, é o sentido que faz com que se venda". (BARTHES, 2009, p.31). Assim, é o processo conotativo, metafórico que opera na construção de um valor simbólico presente em processo que vai desde a própria denominação (dar nomes a) até a alegoria (conjunto de metáforas) das ilusões que, por mimetismo e fruição, levam ao prazer do texto, termo de inspiração também bartheseana.

Todos esses processos criativos estão articulados na moda pelo corpo e pelo vestuário. É como se a moda fosse a 'reinscrição do corpo' (GIL,1997). Nas imagens em análise, o corpo é o articulador dos espaços textuais visuais e o organizador dos materiais residuais em novos tecidos sensíveis que são matéria significante de conteúdo estético e social. É um modo peculiar de construir a identificação pós-moderna, o paradoxo da necessidade e da riqueza, no cenário também paradoxal dos temas de pobreza, exclusão e dificuldade que transparece na obra de Cândido Portinari.

São essas metáforas que formam alegorias imagéticas, ícones de criatividade e inovação que são reconhecidas nas figuras selecionadas para representação do diálogo que Ronaldo Fraga faz com Cândido Portinari. As formas geométricas, os balões de festas de São João e as pipas empinadas pelas crianças da cidade, são motivos presentes na obra de Cândido Portinari, pelo resgate que faz de suas experiências da infância passada na cidade natal. São triângulos, retângulos e formas arredondadas, em diferentes posições, que replicam dados de memória e que trasbordam os limites formais. Não que a geometria não as limite, mas a justaposição irregular das formas é capaz de criar a percepção de alargamento espacial e de reduplicação transformadora. É o que a estética, de inspiração cubista, consegue construir.

A Figura 1 ( $a$ e b), a seguir apresentada, é um exemplo das linhas pluridirecionadas que formam sensações espaciais ampliadas, da transparência na textura, de certa rusticidade, e do volume, conjunto que migra da tela ao vestuário. 
Figura 1a: CP

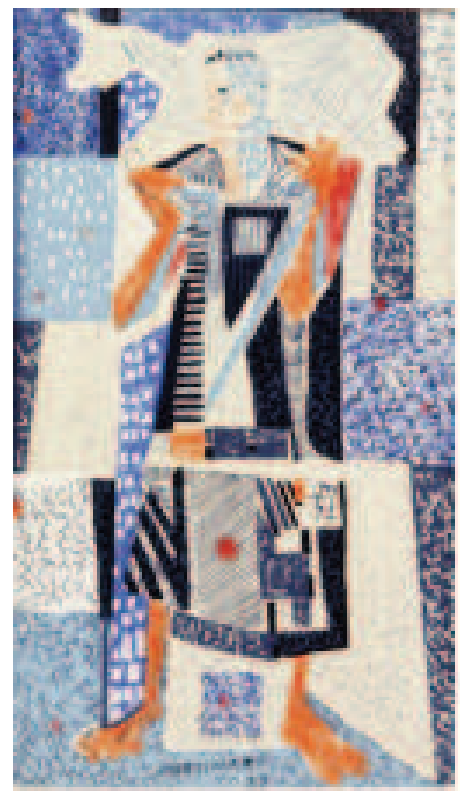

Fonte: CP e RF: Os corpos e a geometria (http://www.portinari.org.br e http://ffw.com.br/ desfiles/sao-paulo/verao-2015, acesso em março de 2015).

As cores, que em Cândido Portinari também remetem ao céu ou às realidades de sua terra natal, constituem um traço que redunda nas peças da coleção de Ronaldo Fraga. Essa ressignificação traz dados da memória na construção das percepções, então complementadas pelas festas infantis documentadas pelas brincadeiras de roda e de pipas. Alegria e liberdade estão sintetizadas na padronagem do tecido e na tautologia da geometria e da cor.

Na Figura 2 ( $a$ e b), a seguir, é 'gentil' a expressão produzida; são cores que relevam a linguagem dos tons e das intensidades. Há um certo tom de sedução e leveza flutuando entre os significantes corpóreos e objetuais. Parece tela em aquarela. A delicadeza dos traços, esguios em sua forma e suaves em suas tonalidades, atualizam no contexto (texto) as estratégias de situação (entorno), fatores que trazem à narrativa imagética elementos relevantes para a produção dos sentidos metafóricos. 
Figura 2a: RF

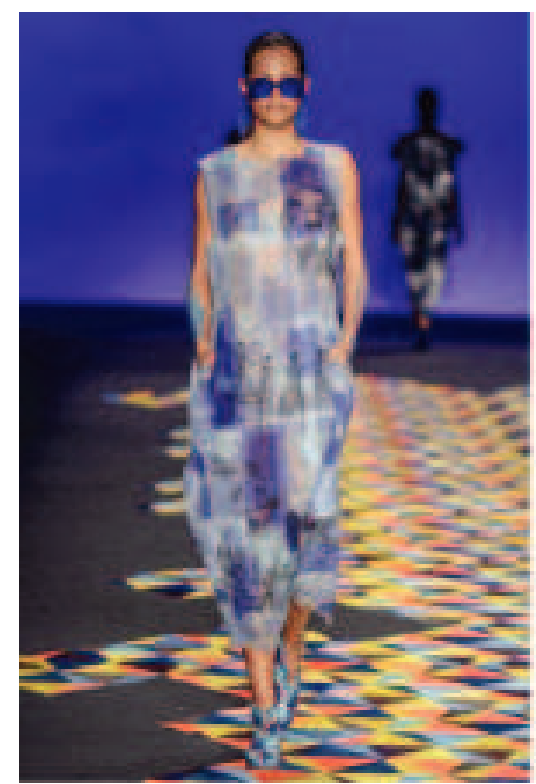

Figura 2b: CP
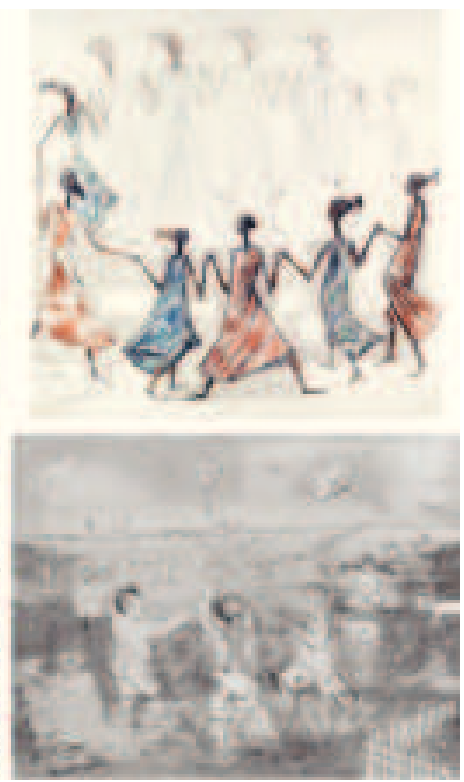

Fonte: RF e CP: As formas e os rabiscos (http://www.portinari.org.br e http://ffw.com.br/desfiles/sao-paulo/verao-2015).

Na centralidade dessas imagens, não está a face anônima, mas a inserção do autor na brincadeira, indiciada pelos resíduos circundantes que avançam irregular e livremente sobre a figura humana e se espalham em harmonia nas roupas. É um avanço irreverente sobre o templo do corpo que precisa ser dessacralizado para responder à ideologia contemporânea, expressão de tótens, mas rejeição de tabus. São, por exemplo, ouro e beleza como tótens, dissociados, de certa forma, dos limites e das restrições decorrentes das proibições.

Modernidade no estilo e identificação são trabalhadas por Touraine (1994), para quem, não seria apenas sobre espaços fixos, racionalizados, com referências históricas, identitárias ou culturais que se formaria esse painel, mas sobre espaços de diversidade e de recomposição, cujos elementos, libertados das referências e da univocidade, produzem interações sensíveis e inaugurais, compondo o mosaico de cenários contemporâneos.

Pipas e rabiscos, nos formatos das calças, saias, blusas e outras peças de vestuário, representam a estruturação e o volume, na expressão de organizada leveza, sensação que emana dos tecidos e das formas esguias e triangulares das meninas na brincadeira de roda. Bolsa-pipa e fitas coloridas ressiginificam o brinquedo, na redundância dos losângos e triângulos superpostos. É, mais uma vez, uma expressão forte e macia, simultaneamente. A religação, aqui, é feita pela Figura 3 ( $a$ e b): 
Figura 3a: RF

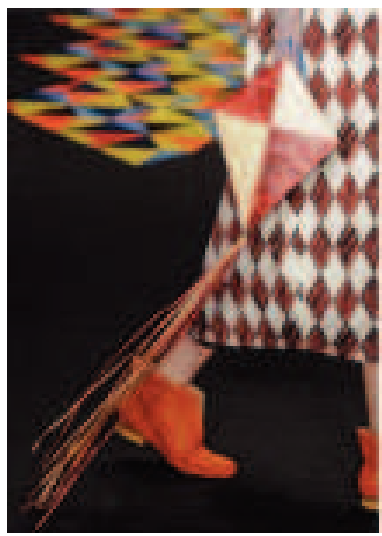

Figura 3b: CP

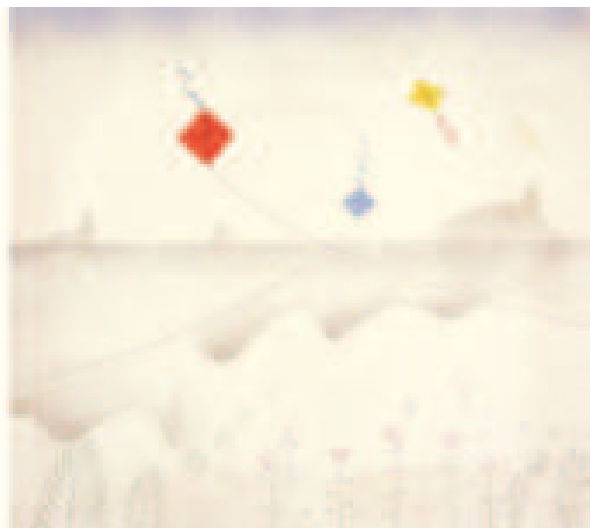

Fonte: RF e CP: As pipas e as fitas (http://www.portinari.org.br e http://ffw.com.br/desfiles/ sao-paulo/verao-2015, acesso em março de 2015).

Essa é uma construção em que aparece uma entre as várias inspirações decorrentes do acesso que Ronaldo Fraga teve ao Caderno de Portinari. Na tentativa de reproduzir os rabiscos do pintor, feixes de fios soltos, como movidos pelo vento, criam a percepção de uma terceira dimensão. De certa forma, as Figuras apresentadas, mimetizam nas metáforas cenas típicas do nordeste brasileiro, expressas em grafismos, geometrias coloridas e linhas desfiadas.

É na definição do simbólico como forma preferencial de operações significativas que aparece a figura da metáfora como fonte de conhecimento e de emoção. Seu formato em sequência de alegorias (narrativa), as metáforas expressam cores e formas que remetem à estética da carnavalização, como simulacro e réplica de fragmentos da realidade social. São registros sincrônicos que funcionam como fonte de interpretação histórica, e que assumem o caráter de documento, de 'testemunho' (LYOTARD, 1990, p.38).

A Figura 4 (a e b), centralizada nos piões, retorna às brincadeiras infantis, agora como metonímia, ou seja, como um termo que remete a um todo narrativo pelo laço da analogia: o pião pela infância. Mostra, também, outro uso da cor, com suave-intensidade de tons que parecem ensaios sobre o esboço desenhado por Cândido Portinari. As formas e volumes sofrem releitura, pois há uma esfericidade triangular que dá movimento; os materiais em contraste destacam esses elementos tão presentes na estética modernista.

Figura 4a: RF

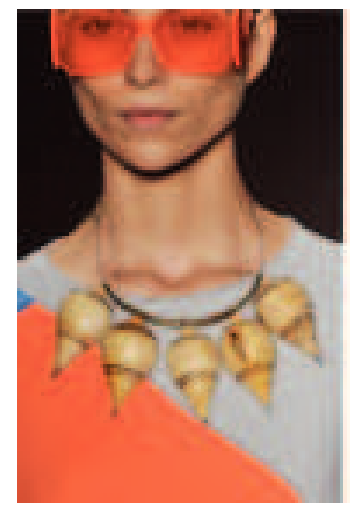

Figura 4b: CP

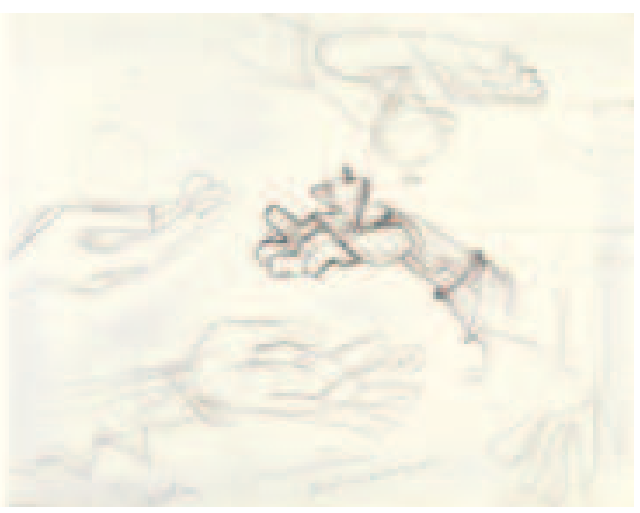

Fonte: RF e CP: Os piões (http://www.portinari.org.br e http://ffw.com.br/desfiles/sao-paulo/ verao-2015, acesso em março de 2015). 
É Fontanille (2005) quem trabalha, no plano da expressão, o modo como o conjunto de figuras (imagens) semióticas forma arranjos visuais pela iconicidade da imagem e pela estabilização da forma. O potencial significativo dessas figuras/ imagens - de sintaxe e retórica polissensorial decorre do entorno, de que se tem informações e do contexto que rege a organização da narrativa. No caso do material aqui selecionado para análise, são eles que, ao fazer dialogar moda e arte, garantem atualidade constante aos conteúdos propostos.

A Figura 5 (a e b) apresenta a lona do circo como metonímia da presença do circo na cidade, que é mais uma reminiscência bucólica de uma infância se não perdida, passada. Difuso na imagética da tela, a expressão circense fica destacada sobre o fundo mais claro na peça do vestuário. O contraste com as formas geométricas coloridas que revestem o piso da passarela cria uma frase de diálogo entre cores e formas (blusa e chão); já os fios-rabiscos estabelecem a linha de continuidade da inspiração da tela de Cândido Portinari, ao lado apresentada.

Figura 5a: RF

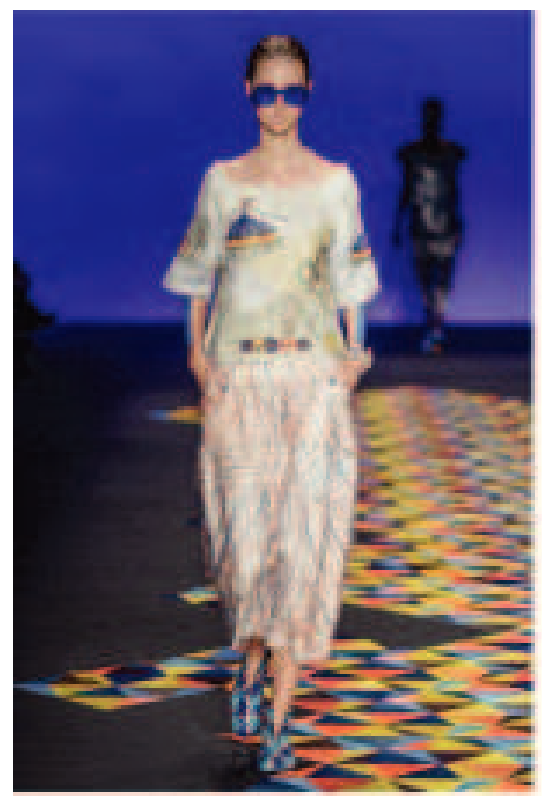

Figura 5b: $\mathrm{CP}$

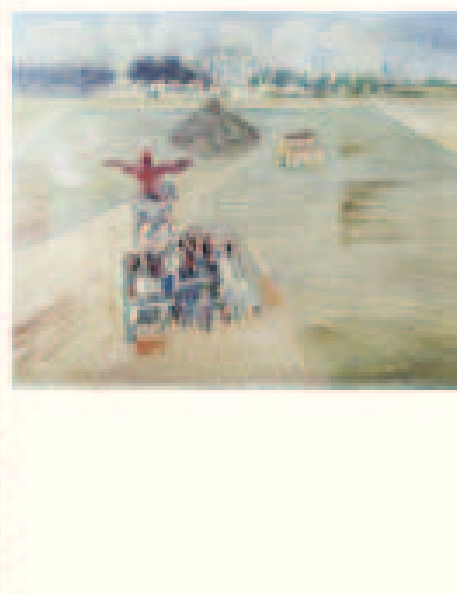

Fonte: RF e CP: O circo e a festa (http://www.portinari.org.br e http://ffw.com.br/desfiles/ sao-paulo/verao-2015, acesso em março de 2015).

O material em análise evoca o hedonismo, tema tratado por Maffesoli (1996) como aparência e frivolidade, embora ambas consistentes. De certa forma, imprime à moda, por exemplo, um novo sentido de consumo e luxo. Trata-se de um hedonismo do cotidiano irreprimível e poderoso que subentende e sustenta toda a vida em sociedade. É uma realidade ao mesmo tempo bem viva e em pleno crescimento. As imagens de todos os discursos do social e de todas as linguagens estruturam-se no dinamismo da transformação a idéia de continuidade, o que faz eco às proposições sobre espaço textual que fundamentam este trabalho. É assim também que Ronaldo Fraga recupera Cândido Portinari.

Em síntese, o prazer dos olhos (tactilidade e visibilidade como apelos plásticos) levam o pensamento a fluir, mas também a conhecer, a expressar as diversas verdades das coisas. Adquire, então, o valor de testemunho, por isso inscrito na história. De certa forma, replica os quatro pivôs essenciais de Maffesoli (1996, p. 145) como estruturantes da estética social: "a prevalência do sensível, a importância do ambiente ou do espaço, a procura do estilo e a valorização do sentimento tribal". 


\section{CONSIDERAÇÕES FINAIS}

Este artigo é parte de um projeto de pesquisa maior em andamento que pretende desenvolver, de maneira mais elaborada, a metodologia de análise aqui referida. Essa proposta destaca conceitos produtivos como intertextualidade, narrativa, linguagens, conotação, referências, testemunho e modernidade; remete aos tótens dessa modernidade e à necessária discussão entre regra e transgressão; reconhece a presença das referências simbólicas e das construções estéticas em todo o tipo de produção humana, da obra de arte às expressões populares; identifica o potencial do estudo semântico das linguagens icônicas, no plano da expressão; desformata o signo, ao conferir independência e mobilidade aos significantes sob forma de cadeia; atualiza os valores emocionais fixos de temática como terra natal, infância e jogo, expressões de efeitos lúdicos e hedonistas; localiza a questão autoral, ou seja, a presença de um eu discursivo que é da ordem da subjetividade; menciona o hibridismo das linguagens de efeitos polissensoriais; enfim, coloca, como viés, o processo projetual em design e a compreensão das realidades como ecossistemas humanos criativos. Indicadas essas direções de pesquisa, resta desenvolvê-las em duas direções: na densidade da formulação teórica e no desenho de metodologia de design.

Cabe referir, ainda, o fato de se considerar a transdisciplinaridade como dado relevante para a compreensão dos artefatos, no sentido que lhe foi atribuído por Morin (2002). Nessa perspectiva, o diálogo entre todas as instâncias do saber é condição de conhecimento expressa na 'religação dos saberes', fundamental, também, para as atividades de pesquisa e projetação no campo da moda. Nessa perspectiva, a área de Design é sensível a essa abordagem pela significação que confere aos processos projetuais criativos, às representações simbólicas, às culturas, aos usuários, às estratégias, à sociedade, ao mercado, às interações sociais, ao consumo, à comunicação, à estética, às condições tecnológicas e aos processos de gestão, todos esses segmentos vistos como substratos do processo de projetação.

À guiza de finalização, materiais: - resíduos, formatos, cores, técnicas, mediações, tecnologias ou molduras: e conceitos - visualidade, significantes flutuantes, linguagens, metáforas, paradigmas, sistemas ou sincronias, tematizam o conteúdo deste texto, materializado na síntese de seu título: "Moda: Expressão de arte e design".

\section{REFERÊNCIAS}

BARTHES, R. 0 sistema da moda. Soa Paulo: Martins Fontes, 2009.

DERRIDA, J. Gramatologia. São Paulo: Perspectiva, 2013.

GIL J. Metamorfoses do corpo. Lisboa: Relógio D’Água, 1997.

LYOTARD, J.F. Moralidades pós-modernas. Campinas: Papirus, 1996.

MAFFESOLI, M. No fundo das aparências. Petrópolis: Vozes, 1996.

MORIN, E. A religação dos saberes: $\mathbf{o}$ desafio do século XXI. Rio de Janeiro: Bertrand Brasil, 2002.

PRADO COELHO. E. Introdução a um pensamento cruel: estruturas, estruturalidade e estruturalismos. In: Estruturalismo: antologia de textos teóricos. Barcelos: Portugalia, 1968.

TOURAINE, A. A crítica da modernidade. Petrópolis: Vozes, 2007.

VERGANTI, R. Meanings and Radical Innovation: a Metamodel and a Research 
Agend. The journal of product Inonovation Management. Vol. 25, p. 436456.2008.

ZURLO, F. Design estratégico. In: AA. W. Gli spazi e le arti, v. IV, Opera XXI Secolo. Roma: Editore Enciclopedia Treccani, 2010.

\section{lone Bentz}

Doutora em Linguística e Semiótica pela Universidade de São Paulo, BR., Estágio pós-doutoral na Université de Paris 3, Sorbonne, Mestre em Teoria Literária pela Pontfícia Universidade Católica de Porto Alegre, RS., Especialista em Teoria Literária pela Universidade de Lisboa ( Fundação Calouste Gulbenkian), Graduação em Letras. Tem experiência em docência, pesquisa e orientação ( mestrado e doutorado) nas áreas de Linguística e Comunicação, com ênfase em sistemas de linguagem, processos de significação e linguagens sincréticas. Atualmente, é professora pesquisadora e orientadora no curso de Pós-graduação em Design, nível de Mestrado, integrante da Escola Indústria Criativa da Universidade do Vale do Rio dos Sinos e integra o Grupo de Pesquisa "Design Estratégico para inovação cultural e social", inscrito no diretório do CNPq. Atua em docência na Graduação de Design, Moda e Produtos, na disciplina Semiótica Aplicada; orienta bolsistas de Iniciação Científica em projetos de Design e de Moda. Desenvolve ( 2014/2017) o projeto de pesquisa "Os fundamentos teóricos do design estratégico: reflexão crítica e experiência de pesquisa aplicada" e, no âmbito do Grupo de Pesquisa, coordena o sub-projeto de pesquisa aplicada "Mulheres do Quilombo do Areal ( POA): práticas criativas artesanais em design para qualificação e inovação".

. A arte no espaço urbano: narrativas visuais. Strategic Design Research Journal, v. 7 (1), p. 07-14, 2014.

Preliminary Studies ion Innovation in Services from the Strategic Design perspective. Strategic Design Research Journal, v. 4, p. 127-131, 2011.

3.. Os processos de projeto: as mediações na construção dos efeitos de sentidos. Design: matrizes interpretativas. 1ed. Porto Alegre: Entremeios Editora, 2015, v. 1, p. 13-27.

4..Design and Semiotics in Dialogue. In: Dijon de Moraes, Regina A. Dias e Rosemary Sales. (Org.). Diversity:design/humanities. Proceding of fouth International Forum for Design as a Process. 1ed.Belo Horizonte: EdUEMG- Universidade do Estado de Minas Gerais, 2014, v. 1, p. 5-.

5. .Cultura pela Semiótica. In: Alexandre Rocha da Silva e lone Bentz. (Org.). Percursos Semióticos: significação, codificação, semiose e interface. 1ed.São Paulo: Kazuá, 2012, v. 1º, p. 27-46.

\section{Fábio Parode}

Doutor em Estética pela Université de Paris 1 - Panthéon Sorbonne (2005), mestre em Ciências da Comunicação pela UNISINOS (2000), Especialista em Design Estratégico pela UNISINOS (2008), graduação em Comunicação Social Jornalismo pela Pontifícia Universidade Católica do Rio Grande do Sul (1992). Tem experiência na área de Comunicação, com ênfase em Estética e Comunicação, atuando principalmente nos seguintes temas: arte, estética e comunicação, comunicação visual e design. Atualmente é professor na Universidade do Vale do Rio dos Sinos-UNISINOS-, na Graduação e Pós-graduação em Design, na linha de pesquisa Processos de projetação de contextos criativos; Realiza pesquisa sobre tendências em design, estética e sustentabilidade. Foi editor do periódico científico Strategic Design Research Journal, www.unisinos.br/sdrj, de 2008 até 2014. Integra o Grupo de Pesquisa "Design Estratégico para inovação cultural e social", inscrito no diretório do CNPq.

Principais artigos publicados: Fábio Parode 
1- $\quad$ Imanência e devir-animal na obra de Alexander Mcqueen (2015)

Dobras (Barueri, SP)

2- $\quad$ Arte e Design: indústrias criativas e sustentabilidade (2014)

http://revistas.unisinos.br/index.php/sdrj/article/view/sdrj.2014.71.01/4324 - 2014

3- $\quad$ El desarrollo sustentable en Brasil: cultura, medio ambiente y diseño (2014)

http://fido.palermo.edu/servicios_dyc/publicacionesdc/vista/publicaciones. php?id_publicacion $=2$

4- O design em tempos de Sustentabilidade (2010)

http://www.proarq.fau.ufrj.br/site/cadernos_proarq/cadernos-proarq_14.pdf

5- Design de autor: uma outra comunicação desafiando cultura e midia global (2009)

http://revista.cisc.org.br/ghrebh/index.php?journal=ghrebh\&page=arti-

cle\&op=view\&path\%5B $\% 5 D=35$ 